\title{
Assessment of Platelet Indices in Patients with Neurodegenerative Diseases: Mean Platelet Volume Was Increased in Patients with Parkinson's Disease
}

\author{
Abdulkadir Koçer, ${ }^{1,2}$ Aslı Yaman, ${ }^{3}$ Elvin Niftaliyev, ${ }^{3}$ Hümeyra Dürüyen, ${ }^{3}$ \\ Mehmet Eryılmaz, ${ }^{2}$ and Emel Koçer ${ }^{3}$ \\ ${ }^{1}$ Medical Faculty, Istanbul Medeniyet University, Istanbul, Turkey \\ ${ }^{2}$ Düzce University, Düzce, Turkey \\ ${ }^{3}$ Bezmialem Vakıf University, Istanbul, Turkey
}

Correspondence should be addressed to Abdulkadir Koçer; abdulkadirkocer@yahoo.com

Received 18 July 2013; Revised 10 November 2013; Accepted 11 November 2013

Academic Editor: Hiroyuki Umegaki

Copyright (C) 2013 Abdulkadir Koçer et al. This is an open access article distributed under the Creative Commons Attribution License, which permits unrestricted use, distribution, and reproduction in any medium, provided the original work is properly cited.

\begin{abstract}
Platelets induce chronic inflammation which is a key step in atherosclerosis and may be involved in the progression of neurodegenerative diseases (NDD). We aimed to measure the mean platelet volume (MPV) and platelet count (PLC) in NDD patients. The present study was designed to investigate the platelet function by measuring MPV and PLC in NDD. A total of 182 outpatients with Alzheimer's (AD) or Parkinson's diseases (PD) were included. The control group consisted of 104 healthy subjects. Platelet count was similar between groups. MPV values of PD patients were higher than those of AD patients and controls $(P<0.001)$. MPV correlated negatively with Heohn and Yahr scale (HYS) score $(P<0.001)$. Increased MPV in patients with PD may point to a platelet dysfunction. High-grade inflammation presents with low levels of MPV as seen in PD patients with high HYS scores.
\end{abstract}

\section{Introduction}

Alzheimer's disease (AD) and Parkinson's disease (PD) are the most common progressive neurodegenerative disorders (NDD) in the elderly, and vascular risk factors may be involved in the pathogenesis of both diseases $[1,2]$. It is well known that the disrupted microvascular integrity in brain parenchyma may play a role in the chain of events ending with AD [1-6]. Besides atherosclerosis, many reports suggest that inflammation may be involved in neurodegenerative disorders [7]. Amyloid beta 42 plays a central role in the neurodegenerative process and triggers inflammation in $\mathrm{AD}$. Although molecular basis is not known, interleukins and cytokines may induce the activation of signaling pathways leading to further inflammation, neuronal injury, and later neuronal death [7]. Nonsteroidal anti-inflammatory drug use may decrease the incidence of $\mathrm{AD}$ and this knowledge supports the role of inflammation in $\mathrm{AD}$ pathogenesis [7].
On the other hand, there are conflicting results about PD. The commonly known risk factors are less frequently seen in the patients with PD [8]. Cumulative incidence of ischemic stroke and myocardial infarction is less frequent in PD patients too $[9,10]$. In contrast, some new articles reported that cardiovascular risk factors, such as diabetes mellitus and central obesity, have been associated with Parkinson's disease (PD), but data on blood pressure and PD are still lacking [2, $11,12]$. Qiu et al. suggested that hypertension was associated with an increased risk of PD and optimal control of blood pressure might reduce the incidence of PD in women $[2,11$, 12]. Also we know that the treatment with levodopa increases blood homocysteine, and high levels of homocysteine may be associated with the increased incidence of vascular events in PD [13].

Platelet-induced chronic inflammation is a key step in atherosclerosis and promotes plaque development, intimae hyperplasia, and restenosis [14, 15]. A range of molecules, 
present on the platelet surface and/or stored in platelet granules, contributes to the cross-talk of platelets with other inflammatory cells during the vascular inflammation involved in the development and progression of atherosclerosis $[16,17]$. During the prolonged course of atherosclerotic disease, platelets have an important role not only in the initiation but also in the progression and exacerbations of atherosclerotic disease [15]. Platelet activity can be conveniently estimated by measuring the mean platelet volume (MPV) and platelet count (PLC) [18].

We hypothesized that platelets might have an important role in the development of NDD if there were relationships between atherosclerosis, inflammation, and platelets. To address this, we selected the most commonly known two-different NDD groups, that is, $\mathrm{AD}$ as a prototype of cortical involvement and PD as a prototype of subcortical involvement. We used a case-control method to compare the serum MPV and PLC in NDD patients with those in controls.

\section{Methods}

Patients $(n=385)$ diagnosed with AD and PD were enrolled from January 2010 until September 2012 in the Departments of Neurology at Düzce University Medical Faculty and Bezmialem Vakif University Medical Faculty Hospitals. Data were obtained by clinical interview, physical and neurological examinations in outpatient clinics specialized in neurodegenerative disorders, laboratory exams, and computed tomography or magnetic resonance imaging. Three hundred thirtyfive patients who accepted to be involved in the study and met the diagnostic criteria of probable $\mathrm{AD}$ and $\mathrm{PD}$ according to the established criteria were evaluated [19-21]. Participants who had cancer, abnormal liver and thyroid function tests moderate and severe level of hypertension $(\geq 160 / 100 \mathrm{mmHg})$, uncontrolled diabetes (HbA1C > 8), high levels of total cholesterol $(>200 \mathrm{mg} / \mathrm{dL})$ with BMI $>30$, any other dementia including vitamin B12 deficiency, and previous history of stroke and receiving antiplatelet or anticoagulant therapy and those who were active smokers (smoking 1 pack or more per day) and heavy drinkers were excluded. After the evaluation with the exclusion criteria, 182 outpatients with $\mathrm{AD}(n=89)$ and PD $(n=93)$ were included in the study. The Turkish version of the minimental state examination (MMSE) was used to screen for cognitive impairment of $\mathrm{AD}$ patients $[22,23]$. $\mathrm{PD}$ patients were examined by using Hoehn and Yahr scale (HYS) which is a scale for PD's severity that rates between 0 and 5 based on the level of clinical disabilities [24]. The control group consisted of 104 subjects, who were matched for age and sex without dementia, PD, any other neurodegenerative diseases, stroke, and hematologic disease [25]. Mean blood pressure levels were recorded after a 7-day followup and repeated measurements. Then, the modifiable risk factors determined by physical examination or self-reported current use of antihypertensive medication, cholesterol lowering drugs, or antidiabetic agents were written down in all participants. In addition, drugs used for $\mathrm{AD}$ and PD or other drugs such as antidepressants, which were widely used in this population, were recorded as well. The study protocol was approved by the local ethics committee.
The aims and procedures of the investigation were orally explained and a consent form was taken from all participants or relatives.

After the 12-hour fasting, ten milliliters of blood samples was drawn from the antecubital vein in the early morning (between 9:00 and 10:00 a.m.), and the samples were analyzed at 13:00 p.m. We measured the MPV and platelet count in a blood sample collected in citrate $(1: 4 \mathrm{vol} / \mathrm{vol})$ to avoid the platelet swelling induced by EDTA. The expected values for PLC and MPV in our laboratory ranged from 140 to $450 \times 10^{3} / \mu \mathrm{L}$ and from 7 to $11 \mathrm{fL}$, respectively. Laboratory exams included complete blood count, chemical profile, blood fasting glucose, total cholesterol, thyroid stimulating hormone, and vitamin B12 levels.

\section{Statistical Analyses}

Descriptive analyses were presented by using means and standard deviations for normally distributed variables. ANOVA test was used to compare normally distributed variables (MPV) between the patients and control groups. Descriptive analyses were presented by using medians and Kruskal Wallis test was used to compare nonnormally distributed variables (PLC and all other variables shown in Table 1) between the patients and control groups. Spearman's correlation analysis was made to evaluate the relationships between MPV and the other findings in $\mathrm{PD}$ and $\mathrm{AD}$ patients. Data were analyzed to identify whether MPV was independently associated with age, blood glucose, cholesterol and thyroid stimulating hormone levels, PLC, and HYS score by using univariate logistic and stepwise multivariate logistic regression models in PD. Odds ratios and $95 \%$ confidence intervals were estimated for the effect of independent variables. A $P$ value $<0.05$ was accepted to be statistically significant.

\section{Results}

One hundred and forty-one participants were female and 145 were male. Demographic and clinical characteristics of patients and controls participating in the study are shown in Table 1. Mean PLC was similar between groups. However, MPV values of PD patients were higher than those of $A D$ patients and controls (Figure 1, $P<0.001$ ). Mean MPV values of $\mathrm{PD}, \mathrm{AD}$, and controls were $10.26 \pm 1.91,9.11 \pm 1.48$, and $9.49 \pm 1.33 \mathrm{f} / \mathrm{L}$, respectively $(F: 20.77, P<0.001)$. The mean differences between $\mathrm{PD}$ and $\mathrm{AD}$ and controls were calculated as 1.48 and $1.09 \mathrm{fL}$, respectively $(P<0.001)$. The presence of risk factors was similar between $\mathrm{PD}$ and $\mathrm{AD}$ groups (Table 1).

In $\mathrm{AD}$ patients, MMSE minimental state examination score was $17.56 \pm 4.68$ and the analysis of the relationships between MMSE scores and MPV or platelet counts did not reveal any significant result. By Spearman analysis, MPV correlated with the PLC $(r:-0.38, P<0.001)$, age $(r:-0.21$, $P=0.04)$, presence of hypercholesterolemia $(r:-0.22, P=$ $0.038)$, and presence of antidepressant use $(r: 0.25, P=0.017)$ in AD patients. The other relationships between MPV or PLC and presence of hypertension or hyperglycemia, the other drugs used for $\mathrm{AD}$ and gender were nonsignificant. 
TABle 1: Demographic and clinical characteristics of participants.

\begin{tabular}{|c|c|c|c|c|}
\hline Characteristics & Group & Median & Min-Max & $P$ value \\
\hline \multirow{3}{*}{ Gender (male/female) } & $\mathrm{AD}$ & $40 / 49^{*}$ & & \multirow{3}{*}{0.25} \\
\hline & $\mathrm{PD}$ & $46 / 47^{*}$ & & \\
\hline & Control & $59 / 45^{*}$ & & \\
\hline \multirow{3}{*}{ Age (year) } & $\mathrm{AD}$ & 75 & $46-88$ & \multirow{3}{*}{0.052} \\
\hline & $\mathrm{PD}$ & 73 & $55-87$ & \\
\hline & Control & 72 & $60-86$ & \\
\hline \multirow{3}{*}{ Platelet count $\times 10^{3} / \mathrm{mm}^{3}$} & $\mathrm{AD}$ & 237 & $122-467$ & \multirow{3}{*}{0.64} \\
\hline & $\mathrm{PD}$ & 230 & $102-561$ & \\
\hline & Control & 250 & $143-470$ & \\
\hline \multirow{3}{*}{ Fasting blood glucose level (mg/dL) } & $\mathrm{AD}$ & 103.5 & $80-184$ & \multirow{3}{*}{0.56} \\
\hline & $\mathrm{PD}$ & 104 & $77-271$ & \\
\hline & Controls & 110.5 & $75-288$ & \\
\hline \multirow{3}{*}{ Total cholesterol level (mg/dL) } & $\mathrm{AD}$ & 114 & $86-174$ & \multirow{3}{*}{0.06} \\
\hline & $\mathrm{PD}$ & 105 & $66-172$ & \\
\hline & Controls & 95 & $79-172$ & \\
\hline \multirow{3}{*}{ Number of the patients with hypertension $(+/-)$} & $\mathrm{AD}$ & $29 / 60^{*}$ & & \multirow{3}{*}{0.003} \\
\hline & $\mathrm{PD}$ & $38 / 55^{*}$ & & \\
\hline & Control & $15 / 89^{*}$ & & \\
\hline \multirow{3}{*}{ Number of the patients with hyperglycemia $(+/-)$} & $\mathrm{AD}$ & $18 / 71^{*}$ & & \multirow{3}{*}{0.004} \\
\hline & $\mathrm{PD}$ & $25 / 68^{*}$ & & \\
\hline & Control & $6 / 98^{*}$ & & \\
\hline \multirow{3}{*}{ Number of the patients with hypercholesterolemia $(+/-)$} & $\mathrm{AD}$ & $7 / 82^{*}$ & & \multirow{3}{*}{0.81} \\
\hline & $\mathrm{PD}$ & $16 / 77^{*}$ & & \\
\hline & Control & $10 / 94^{*}$ & & \\
\hline \multirow{3}{*}{ Number of the patients with antidepressant use $(+/-)$} & $\mathrm{AD}$ & $35 / 54^{*}$ & & \multirow{3}{*}{$<0.001$} \\
\hline & $\mathrm{PD}$ & $34 / 59^{*}$ & & \\
\hline & Control & $0 / 98^{*}$ & & \\
\hline MMSE score & $\mathrm{AD}$ & 18 & $6-26$ & \\
\hline HYS score & $\mathrm{PD}$ & 2 & $1-4$ & \\
\hline
\end{tabular}

${ }^{*}$ Number of the patients; $(+/-)$ : present/not present; MMSE: minimental state examination; HYS: Hoehn and Yahr scale; AD: Alzheimer's disease; PD: Parkinson's disease.

In the statistical analysis of PD patients, MPV correlated with the PLC $(r:-0.36, P<0.001)$, HYS score $(r:-0.32, P=$ $0.002)$, and presence of antidepressant use $(r: 0.31, P=0.003)$. The relationship between MPV and age was not significant $(P>0.05)$. There was a positive correlation between MPV value and the presence of hypercholesterolemia $(r:-0.26, P=$ 0.01 ). The other relationships between MPV or PLC and other vascular risk factors, gender and treatment regiments related to $\mathrm{PD}$ were not significant. In stepwise multivariate analysis, PLC (Beta value $=-0.38, P=0.001$ ) and HYS score (Beta value $=-0.39, P=0.002)$ independently predicted MPV in the patients with $\mathrm{PD}$.

\section{Discussion}

Peripheral blood cells, such as platelets or lymphocytes, have been widely studied in several neuropsychiatric disorders previously [26]. Platelets and their secreted products intervene in inflammation and tissue regeneration [14]. In addition, platelets are the main source of 5-hydroxytryptamine

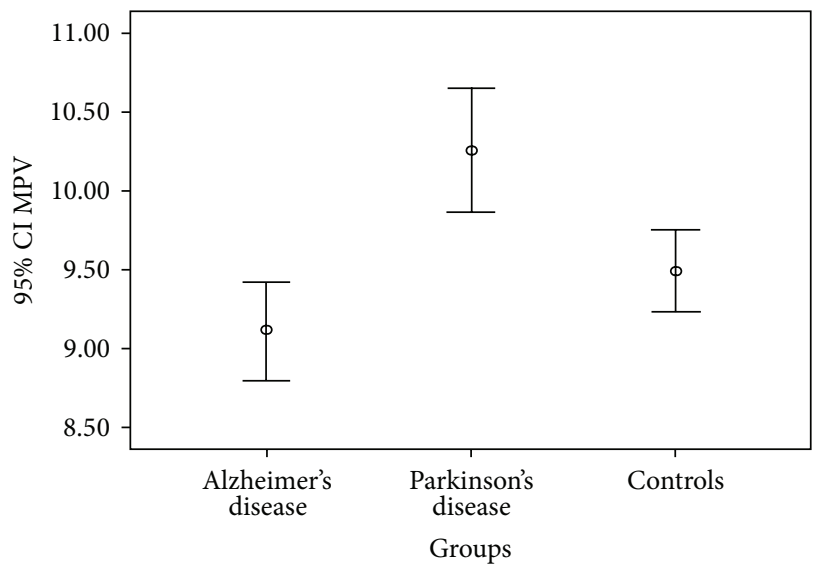

FIGURE 1: Comparison of mean platelet volume (MPV) values.

(5-HT) and contain all the enzymatic machinery to amyloid precursor protein (APP) processing [27]. Platelet dysfunction 
and APP processing abnormalities are believed to occur rather early during the course of $\mathrm{AD}[1,28,29]$. Similarly, Inestrosa et al. reported that platelets were elevated in comparison to nondemented healthy individuals and concluded that platelets might provide a systemic marker of $\mathrm{AD}$ [30]. In vascular dementia, PLC showing platelet activity was decreased and MPV was increased [31]. However, there are conflicting results about MPV in AD patients. Wang et al. reported decreased MPV level, but Yesil et al. reported increased MPV level in $\mathrm{AD}[32,33]$. It is well known that high MPV associates with low-grade inflammatory conditions [34]. Moreover, increased MPV has been reported in patients with myocardial infarction and vascular risk factors [35, 36]. High-grade inflammatory diseases, such as active rheumatoid arthritis or attacks of familial Mediterranean fever, present with low levels of MPV [34]. Our study focused on platelets, MPV, and PLC in AD patients. MPV of AD patients was lower than that of controls, but the difference was not significant. High-risk patients with suspected atherosclerosis were strictly excluded in the present study. Therefore, we think that decreased MPV supported the role of high-grade inflammation in $\mathrm{AD}$ patients. Further studies are needed to explore these conflicting results reported in the literature.

Inflammation is also a neuropathological feature of the Parkinsonian brain. It is believed that the activated glial cells, which compose the majority of this inflammatory response, contribute to the neurodegenerative process through the production of toxic molecules [37]. Longstanding debate with toxicity and oxidative stress is suggested as a cause in $\mathrm{PD}$ $[38,39]$. In the present study, we found that the MPV of PD patients was significantly higher than those of controls and $\mathrm{AD}$ patients (Table 1). Platelets play a crucial role in atherosclerosis and stroke [16-18, 34-36]. The size of the platelets, represented by MPV, has been shown to be closely related to their reactivity, and large platelets are metabolically and enzymatically more active than the small ones, having a higher thrombotic potential [34-36, 40]. Confounding effects on MPV such as patients carrying high risk related to atherosclerosis were carefully excluded in the present study [41]. Because of these strict exclusion criteria, we believe that our finding supports the fact that MPV may be a risk factor for atherosclerosis in the patients with PD. We also found a negative correlation between MPV and PLC as reported previously [34-36, 40]. We have found that antidepressant use was inversely correlated with MPV. This finding was similar to several previous reports suggesting an antiplatelet effect of antidepressant medications [42-44]. In critics, it was difficult to exclude the patients with antidepressant use because a lot of patients were using antidepressants and had depression in both groups. Another important finding of our study was that the progressed PD was correlated with MPV negatively. Decreased MPV during the progression supported the inflammation theory in PD and these findings suggested that there was another problem other than inflammation in the early periods of idiopathic Parkinsonism. To the best of our knowledge, these findings have not been reported previously. So we believe that our results are valuable in clinical followup and decreased MPV reflects inflammation in the pathological stages of PD.

\section{Disclosure}

This study was not sponsored and all authors report no disclosure. The authors declare that there is no conflict of interests. This paper will be partially presented (late breaking poster) at the 17th International Congress of Parkinson's Disease and Movement Disorders.

\section{References}

[1] B. Borroni, N. Akkawi, G. Martini et al., "Microvascular damage and platelet abnormalities in early Alzheimer's disease," Journal of the Neurological Sciences, vol. 203-204, pp. 189-193, 2002.

[2] C. Qiu, G. Hu, M. Kivipelto et al., "Association of blood pressure and hypertension with the risk of parkinson disease: the National FINRISK study," Hypertension, vol. 57, no. 6, pp. 1094-1100, 2011.

[3] R. Pluta, M. Ulamek, and M. Jablonski, "Consideration of the ischaemic basis and treatment of Alzheimer's disease," Folia Neuropathologica, vol. 48, no. 1, pp. 11-26, 2010.

[4] R. Pluta, M. Ułamek, and M. Jabłoński, "Alzheimer’s mechanisms in ischemic brain degeneration," The Anatomical Record, vol. 292, no. 12, pp. 1863-1881, 2009.

[5] G. Tesco, Y. H. Koh, E. L. Kang et al., "Depletion of GGA3 stabilizes BACE and enhances $\beta$-secretase activity," Neuron, vol. 54, no. 5, pp. 721-737, 2007.

[6] M. Jabłoński, R. Maciejewski, S. Januszewski, M. Ułamek, and R. Pluta, "One year follow up in ischemic brain injury and the role of Alzheimer factor," Physiological Research, vol. 60, supplement 1, pp. 113-119, 2011.

[7] D. Weisman, E. Hakimian, and G. J. Ho, "Interleukins, inflammation, and mechanisms of Alzheimer's disease," Vitamins and Hormones, vol. 74, pp. 505-530, 2006.

[8] G. Scigliano, M. Musicco, P. Soliveri, I. Piccolo, G. Ronchetti, and F. Girotti, "Reduced risk factors for vascular disorders in Parkinson disease patients: a case-control study," Stroke, vol. 37, no. 5, pp. 1184-1188, 2006.

[9] I. I. Kessler, "Epidemiologic studies of Parkinson's disease: III. A community-based survey," American Journal of Epidemiology, vol. 96, no. 4, pp. 242-254, 1972.

[10] R. J. Marttila and U. K. Rinne, "Arteriosclerosis, heredity, and some previous infections in the etiology of parkinson's disease. A case-control study," Clinical Neurology and Neurosurgery, vol. 79, no. 1, pp. 46-56, 1976.

[11] E. Cereda, C. Pedrolli, C. Klersy, E. Cassani, R. Caccialanza, and G. Pezzoli, "Diabetes and risk of Parkinson's disease," Diabetes Care, vol. 34, no. 12, pp. 2614-2623, 2011.

[12] G. Hu, R. Antikainen, P. Jousilahti, M. Kivipelto, and J. Tuomilehto, "Total cholesterol and the risk of Parkinson disease," Neurology, vol. 70, no. 21, pp. 1972-1979, 2008.

[13] J. D. Rogers, A. Sanchez-Saffon, A. B. Frol, and R. Diaz-Arrastia, "Elevated plasma homocysteine levels in patients treated with levodopa: association with vascular disease," Archives of Neurology, vol. 60, no. 1, pp. 59-64, 2003.

[14] A. T. Nurden, "Platelets, inflammation and tissue regeneration," Thrombosis and Haemostasis, vol. 105, no. 1, pp. 13-33, 2011.

[15] H. F. Langer and M. Gawaz, "Platelet-vessel wall interactions in atherosclerotic disease," Thrombosis and Haemostasis, vol. 99, no. 3, pp. 480-486, 2008.

[16] Y. Huo and K. F. Ley, "Role of platelets in the development of atherosclerosis," Trends in Cardiovascular Medicine, vol. 14, no. 1, pp. 18-22, 2004. 
[17] M. Gawaz, K. Stellos, and H. F. Langer, "Platelets modulate atherogenesis and progression of atherosclerotic plaques via interaction with progenitor and dendritic cells," Journal of Thrombosis and Haemostasis, vol. 6, no. 2, pp. 235-242, 2008.

[18] A. Muscari, S. de Pascalis, A. Cenni et al., "Determinants of Mean Platelet Volume (MPV) in an elderly population: relevance of body fat, blood glucose and ischaemic electrocardiographic changes," Thrombosis and Haemostasis, vol. 99, no. 6, pp. 1079-1084, 2008.

[19] G. McKhann, D. Drachman, and M. Folstein, "Clinical diagnosis of Alzheimer's disease: report of the NINCDS-ADRDA work group under the auspices of Department of Health and Human Services Task Force on Alzheimer's disease," Neurology, vol. 34, no. 7, pp. 939-944, 1984.

[20] American Psychiatric Association, Diagnostic and Statistical Manual of Mental Disorders, American Psychiatric Association, Washington, DC, USA, 3rd edition, 1980.

[21] A. J. Hughes, S. E. Daniel, L. Kilford, and A. J. Lees, "Accuracy of clinical diagnosis of idiopathic Parkinson's disease: a clinicopathological study of 100 cases," Journal of Neurology Neurosurgery and Psychiatry, vol. 55, no. 3, pp. 181-184, 1992.

[22] C. Güngen, T. Ertan, E. Eker, R. Yasar, and F. Engin, "Reliability and validity of the standardized mini mental state examination in the diagnosis of mild dementia in Turkish population," Türk Psikiyatri Dergisi, vol. 13, no. 4, pp. 273-281, 2002.

[23] M. F. Folstein, S. E. Folstein, and P. R. McHugh, “"'Mini-mental state": a practical method for grading the cognitive state of patients for the clinician," Journal of Psychiatric Research, vol. 12, no. 3, pp. 189-198, 1975.

[24] M. M. Hoehn and M. D. Yahr, "Parkinsonism: onset, progression and mortality," Neurology, vol. 17, no. 5, pp. 427-442, 1967.

[25] A. Arıkanoğlu, M. U. Çevik, E. Uzar, A. Acar, E. Akıl, and F. Ekici, "The increase of the mean platelet volume in patients with intracerebral haemorrhage," Turkish Journal of Neurology, vol. 18, pp. 54-56, 2012.

[26] P. Bongioanni, M. Castagna, C. Mondino, B. Boccardi, and M. Borgna, "Platelet and lymphocyte benzodiazepine binding in patients with Alzheimer's disease," Experimental Neurology, vol. 146, no. 2, pp. 560-566, 1997.

[27] B. Borroni, C. Agosti, E. Marcello, M. di Luca, and A. Padovani, "Blood cell markers in Alzheimer disease: amyloid precursor protein form ratio in platelets," Experimental Gerontology, vol. 45, no. 1, pp. 53-56, 2010.

[28] F. Cattabeni, F. Colciaghi, and M. di Luca, "Platelets provide human tissue to unravel pathogenic mechanisms of Alzheimer disease," Progress in Neuro-Psychopharmacology and Biological Psychiatry, vol. 28, no. 5, pp. 763-770, 2004.

[29] A. Kessler, M. Shinitzky, and B. Kessler, "Number of platelet dense granules varies with age, schizophrenia and dementia," Dementia, vol. 6, no. 6, pp. 330-333, 1995.

[30] N. C. Inestrosa, R. Alarcon, J. Arriagada, A. Donoso, and J. Alvarez, "Platelet of Alzheimer patients: increased counts and subnormal uptake and accumulation of $\left[{ }^{14} \mathrm{C}\right] 5$-hydroxytryptamine," Neuroscience Letters, vol. 163, no. 1, pp. 8-10, 1993.

[31] T. Yagi, N. Kohashi, R. Katori, and M. Miyazaki, "Mean platelet volume, platelet count and platelet retention rate in cerebral vascular disease and Alzheimer type dementia," Japanese Journal of Geriatrics, vol. 21, no. 6, pp. 545-549, 1984.

[32] R. T. Wang, D. Jin, Y. Li, and Q. C. Liang, "Decreased mean platelet volume and platelet distribution width are associated with mild cognitive impairment and Alzheimer's disease," Journal of Psychiatric Research, vol. 47, no. 5, pp. 644-649, 2013.
[33] Y. Yesil, M. E. Kuyumcu, M. Cankurtaran et al., "Increased Mean Platelet Volume (MPV) indicating the vascular risk in Alzheimer's Disease (AD)," Archives of Gerontology and Geriatrics, vol. 55, no. 2, pp. 257-260, 2012.

[34] A. Y. Gasparyan, L. Ayvazyan, D. P. Mikhailidis, and G. D. Kitas, "Mean platelet volume: a link between thrombosis and inflammation?" Current Pharmaceutical Design, vol. 17, no. 1, pp. 47-58, 2011.

[35] S. Greisenegger, G. Endler, K. Hsieh, S. Tentschert, C. Mannhalter, and W. Lalouschek, "Is elevated mean platelet volume associated with a worse outcome in patients with acute ischemic cerebrovascular events?" Stroke, vol. 35, no. 7, pp. 1688-1691, 2004.

[36] N. M. Smith, R. Pathansali, and P. M. W. Bath, "Platelets and stroke," Vascular Medicine, vol. 4, no. 3, pp. 165-172, 1999.

[37] S. Przedborski, "Inflammation and Parkinson's disease pathogenesis," Movement Disorders, vol. 25, pp. S55-S57, 2010.

[38] P. S. Whitton, "Inflammation as a causative factor in the aetiology of Parkinson's disease," British Journal of Pharmacology, vol. 150, no. 8, pp. 963-976, 2007.

[39] H. Wilms, L. Zecca, P. Rosenstiel, J. Sievers, G. Deuschl, and R. Lucius, "Inflammation in Parkinson's diseases and other neurodegenerative diseases: cause and therapeutic implications," Current Pharmaceutical Design, vol. 13, no. 18, pp. 1925-1928, 2007.

[40] C. Giles, “The platelet count and mean platelet volume," British Journal of Haematology, vol. 48, no. 1, pp. 31-37, 1981.

[41] A. Muscari, S. de Pascalis, A. Cenni et al., "Determinants of Mean Platelet Volume (MPV) in an elderly population: relevance of body fat, blood glucose and ischaemic electrocardiographic changes," Thrombosis and Haemostasis, vol. 99, no. 6, pp. 1079-1084, 2008.

[42] M.-C. Morel-Kopp, L. Mclean, Q. Chen et al., “The association of depression with platelet activation: evidence for a treatment effect," Journal of Thrombosis and Haemostasis, vol. 7, no. 4, pp. 573-581, 2009.

[43] V. L. Serebruany, A. H. Glassman, A. I. Malinin et al., "Platelet/endothelial biomarkers in depressed patients treated with the selective serotonin reuptake inhibitor sertraline after acute coronary events: the Sertraline Antidepressant Heart Attack Randomized Trial (SADHART) platelet substudy," Circulation, vol. 108, no. 8, pp. 939-944, 2003.

[44] A. Flöck, A. Zobel, G. Bauriedel et al., "Antiplatelet effects of antidepressant treatment: a randomized comparison between escitalopram and nortriptyline," Thrombosis Research, vol. 126, no. 2, pp. e83-e87, 2010. 


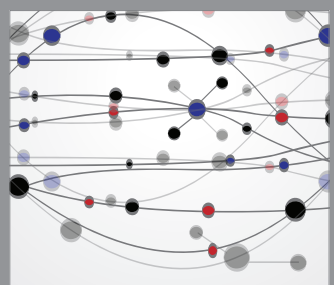

The Scientific World Journal
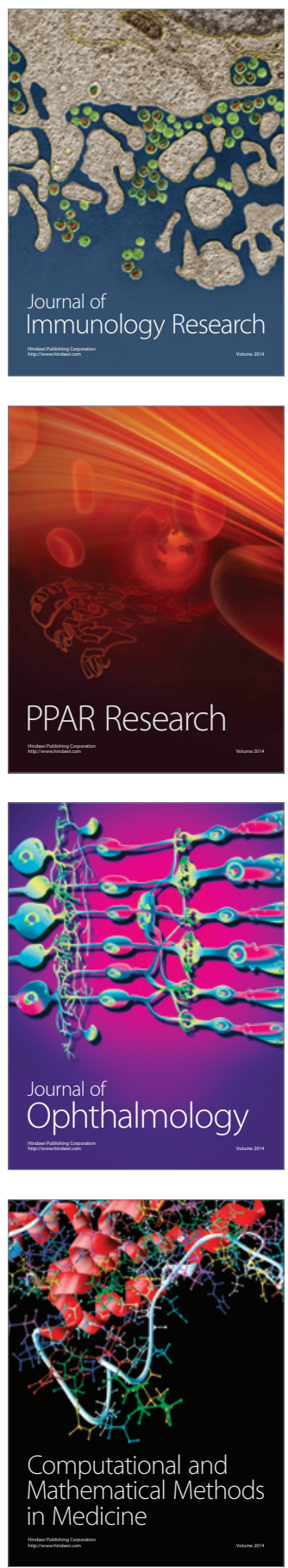

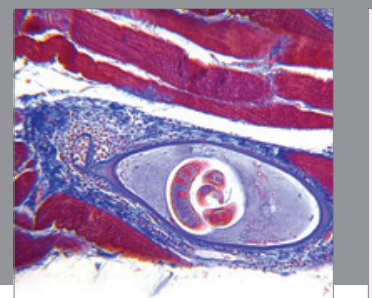

Gastroenterology

Research and Practice
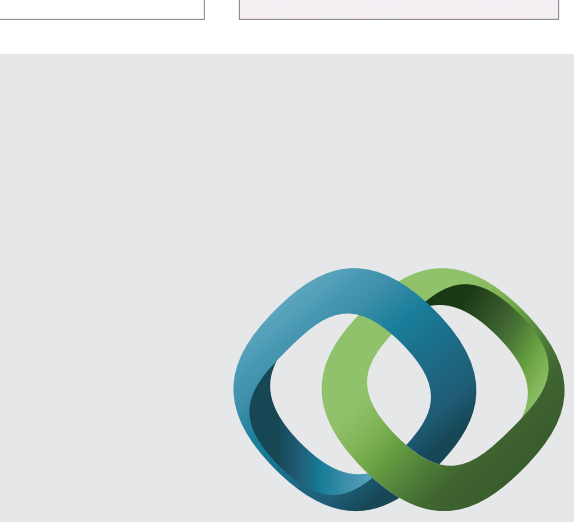

\section{Hindawi}

Submit your manuscripts at

http://www.hindawi.com
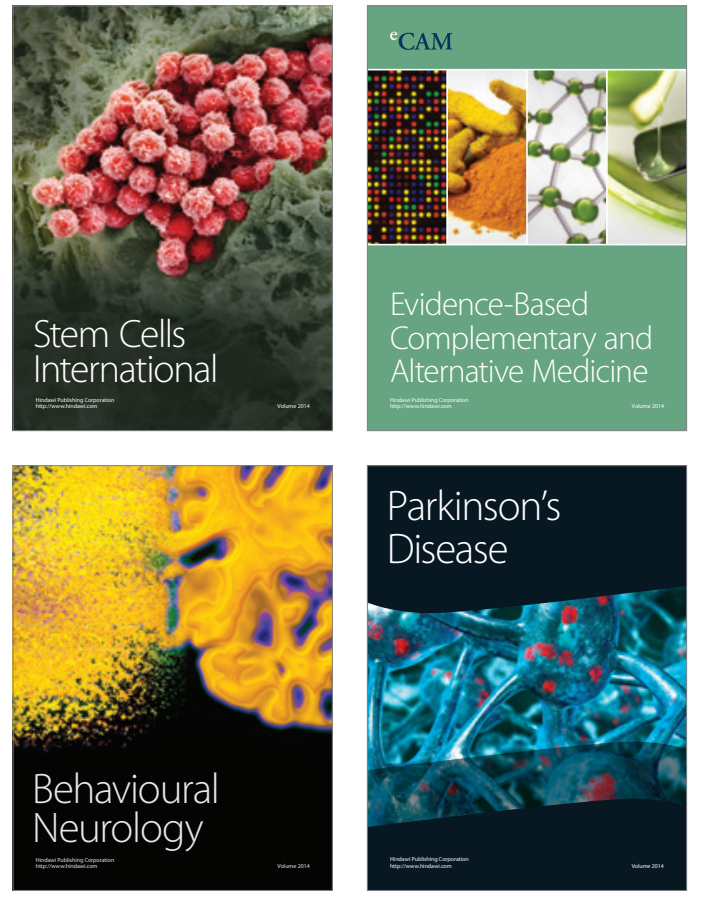
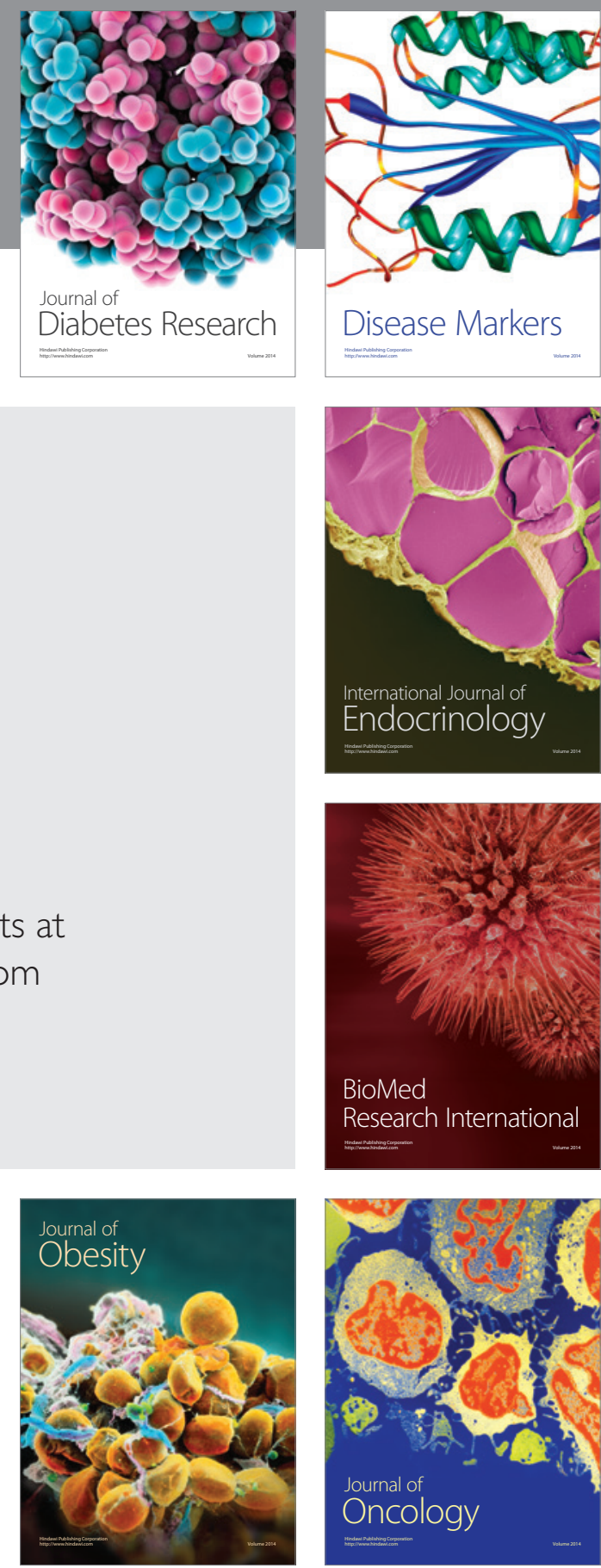

Disease Markers
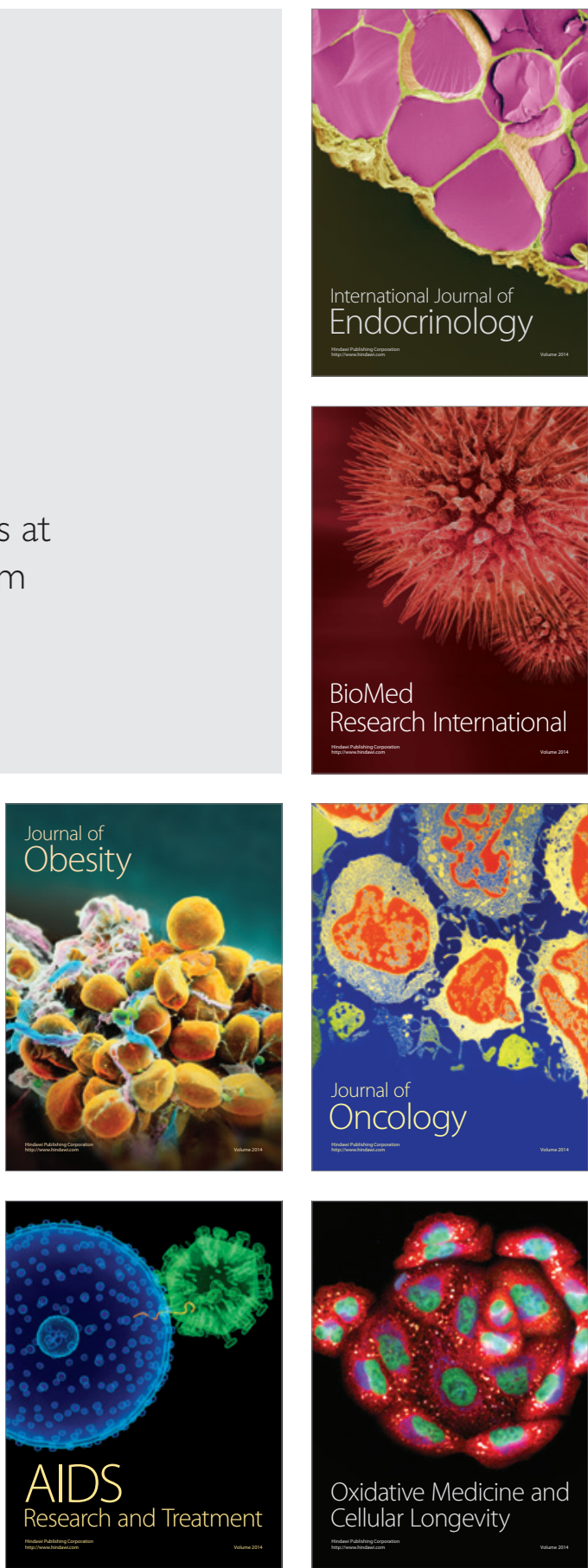